\title{
Scientific Knowledge Networks in Peripheral Regions and Local Innovation Systems:The Case of Chemistry in the State of Bahia
}

\author{
Rogério H. Quintella', Elizabeth Jorge da Silva Monteiro de Freitas², Andrea Cardoso Ventura ${ }^{3}$, Morjane \\ Armstrong Santos ${ }^{4}$, Daniel Reis Armond de Melo ${ }^{5}$, Gustavo da Silva Motta 6 , Samantha Jucá
}

\begin{abstract}
Scientific production and technological innovation growth in Brazil are not homogeneous in its different regions despite its public policies. The same phenomenon can be observed within the states of the Brazilian Federation. This article examines the diffusion of scientific expertise in six public institutions of science and technology in the state of Bahia between 2004 and 2008. The state is the largest in the north-east of Brazil, an area marked by a semi-arid climate and a low human development index; however, it has a large chemical and petrochemical complex. This article, focusing on the scientific field of chemistry, is based on foundations of innovation and knowledge management, as well as social network analysis, aiming to examine relations between scientific production and institutional, structural and relational characteristics of inter- and intra-institutional scientific knowledge networks. The results show that public policies on science, technology and innovation regarding the peripheral regions need to be rethought.
\end{abstract}

Keywords: Scientific knowledge networks; innovation and scientific production; innovation in peripheral regions.

\footnotetext{
' Universidade Federal da Bahia, NPGA/NACIT/CITECS - Av. Reitor Miguel Calmon S/N,Vale do Canela, 4I I I0-I00, Salvador, Brasil. E-mail: rhquintella@gmail.com.

${ }^{2}$ Universidade Federal da Bahia, NPGA/NACIT/CITECS - Av. Reitor Miguel Calmon S/N,Vale do Canela, 4I I I0-I00, Salvador, Brasil. E-mail: elizabethfreitas@gmail.com

${ }^{3}$ Universidade Federal da Bahia, NPGA/NACIT/CITECS - Av. Reitor Miguel Calmon S/N,Vale do Canela, 4 I I I0-I 00, Salvador, Brasil. E-mail: andreaventurassa@gmail.com

${ }^{4}$ Universidade Federal da Bahia, NPGA/NACIT/CITECS - Av. Reitor Miguel Calmon S/N,Vale do Canela, 4III 0-I00, Salvador, Brasil. E-mail:morjanessa@gmail.com

${ }^{5}$ Universidade Federal da Bahia/ Universidade Federal do Amazonas, NPGA/NACIT/CITECS - Av. Reitor Miguel Calmon S/N,Vale do Canela, 4I I I0-100, Salvador, Brasil. E-mail: daniel.armond@gmail.com

${ }^{6}$ Universidade Federal da Bahia/ Universidade Federal Fluminense, NPGA/NACIT/CITECS - Av. Reitor Miguel Calmon S/N,Vale do Canela, 4I I I0-100, Salvador, Brasil. E-mail:gustavomotta@gmail.com

${ }^{7}$ Universidade Federal da Bahia, NPGA/NACIT/CITECS - Av. Reitor Miguel Calmon S/N,Vale do Canela, 4III 0-I 00, Salvador, Brasil. E-mail:samjuca@hotmail.com
} 


\section{Introduction}

Lundvall (1992) studied and popularized the concept of National Innovation Systems (NIS) as sets of elements and interactive relations of production, dissemination and use of new and economically useful knowledge. Freeman (1995) defined these systems soon after as a network of institutions in public and private sectors, the activities and interactions of which initiate, import, modify and diffuse new technologies.

Many authors deal with the National Innovation Systems in the central countries (Edquist, 1997; Miettinen, 2002; Patel and Pavitt, 1994) and already there is also a considerable amount of research on the subject in developing countries (Albuquerque, 1996; Cassiolato, 1996; Jun, Shanchao and Jin, 20II).

Plonski (1994) discusses this issue for the Latin American reality, analyzing the roles played by universities, companies and governments. According to Plonski, cooperation is perceived by universities as a way, among others, to overcome the insufficiency of traditional sources of funds; it is perceived by companies as capable of providing solutions to deal with the challenges of innovation, and, by governments it is seen as strategically important to the economic and social viability of some regions.

If one examines the issue of scientific research alone, one can realize that there is a growing body of knowledge that has been produced worldwide and socialized through scientific journals. In the last decade or so this growth has been especially significant in developing countries, and among these, particularly in China and Brazil. The Global Research Report - Brazil (Adams and King, 2009, p. 4) "shows that Brazil's output has doubled in ten years to 2007, part of a long-term trend of growth that far exceeds established G7 economies".

The state of Bahia, where this research was conducted, is the fourth largest Brazilian state in terms of population and it accounts for the seventh largest GDP in the Brazilian Federation. It is located in the north-east of the country, in the middle of the semi-arid region, where there are some of the worst Human Development Indexes of the Brazilian states. Although it is clearly a peripheral region, until 2005 Bahia had already six public universities. Among them is UFBA - the Federal University of Bahia - which is the most renowned, emphasizing mainly scientific production, which represented about 85 per cent of the state accumulated production indexed by the ISI Web of Science and Web of Knowledge between 1970 and 2007. Figure I below compares the relative growth of world scientific production, Brazilian scientific production and Federal University of Bahia scientific production between $198 \mathrm{I}$ and 2007 , based on an index I for the production of 1981 .

Lima and Teixeira (200I, p. 155) discuss the concept of the Fragmented Innovation System, applying it to the state of Bahia, and conclude that at the beginning of this century some of the major difficulties of this system are the "industrial structure focused on commodity producers" and the "absence of clear criteria for the allocation of state resources in Science and Technology". In turn, Loiola and Ribeiro (2007) propose a model for the formulation of science, technology and innovation (S,T \&l) policy for the same state.

In the present article is not intended to assess Bahia's innovation system as a whole, but only its main institutions of science and technology - in other words its public universities - in terms of their ability to produce knowledge in the same field as its more prominent industry, the chemical and petrochemical industry. This is a segment of the "concentrated industrial structure", as observed by Lima and Teixeira (200I, p. 155). On the other hand, this article is expected to highlight how the "absence of clear criteria for the allocation of state resources in Science \& Technology" (p. 155) mentioned earlier can be minimized, improving the formulation of S,T \& policies in Bahia as addressed by Loiola e Ribeiro (2007). 


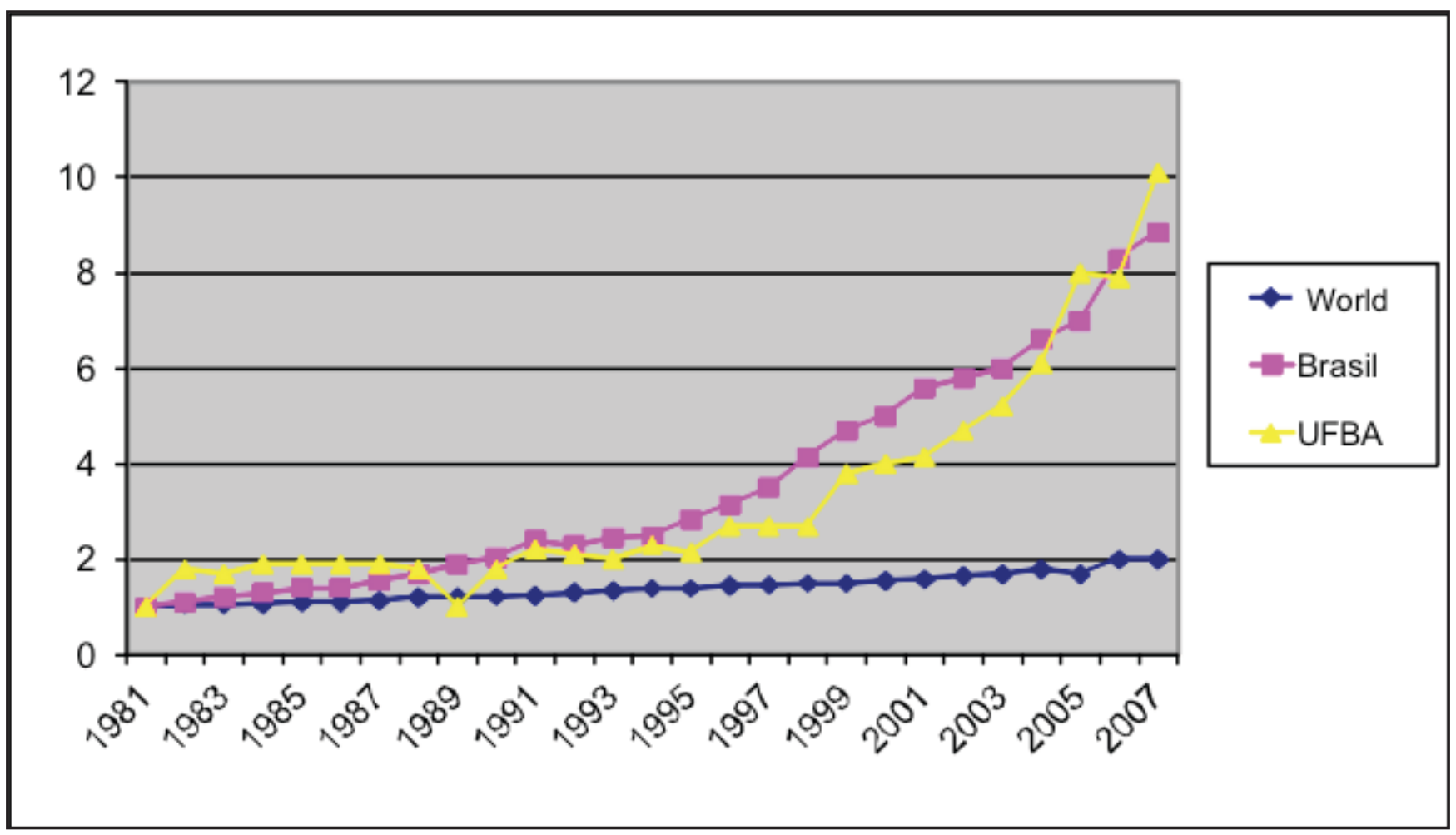

Figure I. Comparative scientific production growth /Source: Author's, elaborated from data from the ISI Web of Knowledge

It is widely recognized that scientific knowledge is produced through networks of research and knowledge (Merton, 1973; Moody, 2004; Wagner and Leydesdorff, 2005). The validation and dissemination of knowledge takes place mainly through publications in scientific journals. On the other hand, approaches such as the seminal work of Leydesdorff and Etzkowitz (1998) and Sabato and Botana (1968) clearly show the importance of the scientific production of universities for technological innovation and, consequently, for economic development. In the context of peripheral countries and outlying regions such importance is even greater, since the research conducted by higher education institutions has a much larger share of total investment in research (Rapini and Righi, 2006) than in most developed countries. Thus, issues related to academic cooperation also become correspondingly more important to the development of regions and states such as Bahia.
This article aims to contribute to the understanding of the functioning of the academic networks of research and scientific knowledge in an area of knowledge of great economic importance in a peripheral region in a developing country. It analyses the operation and roles of scientific knowledge networks of public institutions of higher education in Bahia, using as a proxy the coauthorship networks from these institutions with articles published in journals indexed in the ISI Web of Knowledge in the field of chemistry between 2004 and 2008. The six institutions studied are: the Federal University of Bahia (UFBA), the State University of Bahia (UNEB), the State University of Santa Cruz (UESC), the State University of Feira de Santana (UEFS), the State University of Southwest Bahia (UESB) and the Federal Centre of Technological Education (CEFET), now called the Federal Institute of Education, Science and Technology - Bahia (IFBA)'. ' CEFET is currently named IFBA - Instituto Federal de Educação Ciência e Tecnologia da Bahia. We decided to keep the old denomination
because this is the name that was used when searching for its papers in the ISI Web of Knowledge in the chosen period. 


\section{Theoretical background and literature review}

It is indisputable that knowledge and its management are key issues for the social and economic development of societies and regions. This is why it is increasingly the object of studies and research in various fields such as psychology, engineering, information science, sociology and management, among others.

For Nonaka and Takeuchi (1997) knowledge is divided into two closely-related types. The first, the tacit type, also known as subjective knowledge, is formed by a system of ideas and experiences, the formal, explanation and transfer processes of which are difficult to elaborate. The second, the explicit knowledge, is easier to access and can be transmitted and formalized by means of text, figures, tables and databases. For Nonaka and Takeuchi (1997) the evolution of knowledge has as a basic foundation the cycles of knowledge conversion between tacit and explicit, which they characterized as socialization, externalization ${ }^{2}$, combination and internalization phases. As a complement, Davenport and Prusak (1998) show that the intentional generation of knowledge can be accomplished through five modes: Acquisition, Directed Resources, Fusion, Adaptation and Knowledge Networks, the latter being understood by Skyrme (2003 as cited in Pimenta, Santos, Oliveira, and Queiroz, 2004) as informal and self-organized ${ }^{3}$ around people with common interests to communicate, share knowledge and solve problems together. This present article focuses on the process of socialization identified by Nonaka and Takeuchi (1997), specifically dealing with intentionally-produced knowledge, as studied by Davenport and Prusak (1998), according to the definition of Skyrme (2003 as cited in Pimenta et al., 2004).

Academic research has been increasingly recognized as necessary for the creation and dissemination of knowledge, whether in national innovation systems (Lundvall, 1992) or in local and regional innovation systems (Asheim and Isaksen, 2002). In most scientific papers produced by universities and faculties the researchers make up social networks through interpersonal relationships within their own institutions, as well as through other institutions, in order to improve their learning, to search for more research capabilities, to accelerate the diffusion of knowledge generated by them, and especially to legitimize and get recognition for their personal contributions (Barab, Thomas, and Merrill, 200I; Lee and Bozeman, 2005; Merton, 1973; Moody, 2004; Wagner and Leydesdorff, 2005).

For the analysis of social networks such as those formed by researchers it is necessary to understand the structure as well as the relations that comprise it. The main structural property of a network is its density, which, according to Gnyawali and Madhavan (200I), can be understood by extending the interconnection between the actors, that is, the greater the interconnectedness, the greater the density. Indicators of density together with indicators of centrality and transitivity (the probability of two people being connected) make up the main set of structural properties of social networks. There are three main indicators of centrality: degree represents the number of ties incident upon an actor (a node) in a network; betweenness reflects the number of people an actor is connecting with indirectly through their direct links; closeness represents the average distance or proximity of an actor to the other network actors (Wasserman and Faust, 1994). It is also important to check on the concept of geodesic distance, defined by Barbosa, Byington and Struchiner and (2000) as a measure of the shortest path between nodes.

Networks of scientific knowledge and research, as well as most other social networks, have other key indicators. One is the cohesion, the solidarity and identity of a group, which is conceptualized as a characteristic of homophily (de Nooy, Mrvar, and Batagelj, 2005). Homophily is relatively common in many types of social networks, generating subgroups (cliques) that sometimes have their own norms, values and subcultures. Cliques, in turn, are defined as a sub-network composed of three or more nodes, where all actors are connected directly (Scott, 2000; Wasserman and Faust, 1994). According to some authors who have studied specific scientific knowledge networks, for example, Rossoni and Machado-da-Silva (2007), homophily can lead to homogenization of practices and the presence of a common system of meanings,

\footnotetext{
${ }^{2}$ Scientific production in Brazilian higher education institutions is officially seen as externalization of knowledge since it is one of the main indicators of the governmental quality evaluation of its graduation programmes.

${ }^{3}$ Which may become formalized over time (p. 9).
} 
sometimes so strong that, in the cohesion, it can also be perceived as isomorphism:

Practices are shared and reproduced from the graduate programs, from the formal and informal academic meetings, and from evaluation systems set up in graduate programs, either to assess their quality or in the evaluation of articles submitted to journals and conference proceedings (Worf and Liberman, 1997 as cited in Rossoni and Machado-daSilva, 2007, p. 3).

Structurally, networks can be dense or diffuse, and relationally, they may have strong or weak connections. Weak connections and diffuse networks are more typical in unstable environments because they allow a greater flow of information. On the other hand, strong connections and dense networks are common to stable environments; for them the exchange of information is refined, with a high level of trust, cooperation, reciprocity and social control among stakeholders that can lead to isolation of the group and a possible lack of access of its actors to new information travelling outside the restricted environment.

In a comparative study of graduate programmes and their co-authorship networks in the business administration field in Brazil, Rossoni and Garrido Filho (2009) show growth in cooperation, also concluding that the most productive authors of each programme tend to relate more with each other, which reinforces a third finding: cooperation between programmes is strongly associated with their scientific productivity. As these authors show, the conditioning of scientific activity by groups of researchers has shown the social character of science, which is therefore considered as a collective enterprise not just the result of work of individual researchers.

During the last ten years issues of academic cooperation and co-authorship have been gaining prominence in the understanding of mechanisms that promote scientific development. Hayashi, Hayashi, and Lima (2008), for example, argue that scientific collaboration, especially in the co-authorship of scientific articles, is one of the attributes most researched in social network analysis.

\section{Methodological Strategy}

Once we had defined the object of the analysis as scientific knowledge networks of the public universities of Bahia in chemistry (or related fields, since their scientific production is classified by the Web of Knowledge as Chemistry) and the time frame as between 2004 and $2008^{4}$, we determined which characteristics would be analyzed while potentially impacting on the scientific production of these networks (considering the quantity and quality of this scientific production). At this point we set our presuppositions as:

I. The longer since the foundation of the university (or equivalent) and the existence of undergraduate and postgraduate courses in chemistry (or related areas), the greater the volume and quality of scientific production

2. The greater the number of professors ${ }^{5}$ linked to institutional units (departments and institutes) related to the field of chemistry, the greater the volume and quality of scientific production

3. The greater the number of researchers included in formal research groups listed in the CNPq (National Council for Scientific and Technological Development) Directory of Research Groups, the greater the volume and quality of scientific production

4. The greater the number of researchers awarded $\mathrm{CNPq}$ productivity scholarships ${ }^{6}$ linked to the faculties under review, the greater the volume and quality of scientific production

5. The denser the networks of knowledge and coauthorship, the greater the volume of their scientific production

6. The more dispersed the networks, the higher the presence of non-redundant knowledge in them and, consequently, the better the quality of their scientific production.

\footnotetext{
${ }^{4} 2008$ was chosen because it was the last year we obtained complete data for all of the institutions studied. The initial year (2004) was chosen to take into account the creation of two new graduate programmes in these institutions.

${ }^{5}$ The majority of professors in universities and other public institutions of higher education in Brazil are also researchers since, in most universities, having a doctoral degree is a necessary condition for participating in selective tendering, especially for full-time professors. For this reason along the whole paper the terms "researcher" and "professor" will be used as synonymous.

${ }^{6}$ Less than ten per cent of Brazilian researchers are awarded CNPq scholarships. They are mainly chosen based on their scientific productivity.
} 
Given the kind of presuppositions adopted in this research, a set of independent variables was chosen to be investigated in search of statistical correlations with the dependable variables: the volume and quality of scientific production indexed during the period studied.

Next the list of independent variables was categorized into:

I. Institutional variables: the type of institution (federal or state), the location of the institution (capital or interior), the existence or not of a graduate programme in chemistry.

2. Relational variables: those concerned with the behavior of the network in terms of how the authors and coauthors relate to each other.

3. Structural variables: those related to the structure of co-authorship networks themselves, encompassing network density and centrality.

Extensive research on primary and secondary data was carried out, searching for information related to the institutional characteristics of the six institutions. This research started by collecting information on the websites of the five universities and CEFET. As not all of the data needed was available on these sites, telephone contact was necessary to complete the database, seeking to obtain, for example, the list of professors and other researchers in each unit linked directly to the field of chemistry (or the one that is epistemologically closest to it). In addition, we looked at the $\mathrm{CNPq}$ databases to find out which researchers from each institution were present in formal research groups (working on chemistry) registered in the Council. At this time we also identified researchers listed in research groups from other universities, seeking to verify the existence of homophily in these networks.

In the second stage we began collecting data on the ISI Web of Knowledge7, where co-authorship networks in chemistry-related scientific journals were extracted for the period between 2004 and 2008.
The data extracted from the Web of Knowledge was then audited and exported to UCINET 6.2 software. After this step we analyzed the structure of the networks, their components and, as an example, their measures of centrality and cohesion among authors. Finally, based on the list of articles indexed in the period 2004-2008, we performed a search on the CAPE ${ }^{8}$ Qualis database, identifying their journals' quality score (typically allocated according to their JCR impact factor) according to the chemistry evaluation committee. As a result, we calculated the total score of scientific production from each institution by multiplying the number of articles published in each journal by the score assigned to it in the aforementioned Qualis database.

The following sections present some of the results of this research. In the first section only results relating to the institutional analysis are presented, and the most important independent variables are shown in Tables I, 2 and 3 . The second section presents the results of the scientific production analysis, based on co-authorship of ISI Web of Knowledge indexed journals.

\section{Results of the Institutional Analysis}

This section presents a comparative mapping of scientific production in chemistry among public universities and colleges in Bahia. The correlation between these factors and scientific productivity will be presented in the concluding section of the article. Tables I and 2 show the main results of the institutional analysis.

\footnotetext{
${ }^{7}$ Chosen because of its respectability and coverage.

${ }^{8}$ CAPES is a public foundation responsible for governmental evaluation of graduation programmes in Brazil. It is an extremely complicated system, based mainly on the scientific productivity of each programme's researchers. For this purpose each researcher can only be registered to one institution and therefore has to be a full-time employee of the institution responsible for his/her programme. In order to calculate this productivity, every three years CAPES publishes a classification (named Qualis) where all journals related to the graduation programmes are divided into eight quality levels. A number of points corresponds to each level.
} 


\begin{tabular}{|c|c|c|c|c|c|c|}
\hline Institution & CEFET.9 & UEFS & UESB & UESC & UNEB & UFBA \\
\hline Type & Federal & State & State & State & State & Federal \\
\hline Location & Capital & Interior & Interior & Interior & Capital & Capital \\
\hline U niversity foundation & 1993 & 1976 & 1969 & 1974 & 1979 & 1946 \\
\hline First undergraduate course & 2008 & $\bigoplus$ & 1999 & 1995 & 1998 & 1958 \\
\hline First postgraduate course & $\bigoplus$ & $\bigoplus$ & 2005 & $\bigoplus$ & 2006 & 1968 \\
\hline First indexed paper & 2000 & 1999 & 2001 & 2001 & 1996 & 1974 \\
\hline First formal research group & 1991 & 1989 & 2002 & 1976 & 1980 & 1977 \\
\hline \hline
\end{tabular}

Table I. Institutional Data (related to the field of chemistry) of Public Institutions of Higher Education in Bahia

\begin{tabular}{|c|c|c|c|c|}
\hline Institution & $\begin{array}{l}\text { Technical } \\
\text { Level }\end{array}$ & U ndergraduate D egree & M asterõ D egree & Doctorate \\
\hline UFBA & $\bigoplus$ & $\begin{array}{c}\text { Licence to Teach; B achelorõ } \\
\text { Degree in Chemistry; Industrial } \\
\text { Chemistry }\end{array}$ & $\begin{array}{l}\text { Organic Chemistry; } \\
\text { Inorganic Chemistry; } \\
\text { A nalytical Chemistry; } \\
\text { Physical Chemistry }\end{array}$ & $\begin{array}{l}\text { A nalytical } \\
\text { Chemistry; } \\
\text { Organic } \\
\text { Chemistry }\end{array}$ \\
\hline UESC & 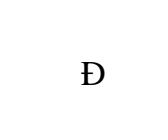 & $\begin{array}{c}\text { Chemical Engineering; L icence to } \\
\text { Teach; B achel orỗ D egree in } \\
\text { Chemistry }\end{array}$ & $\bigoplus$ & $\bigoplus$ \\
\hline UNEB & $\bigoplus$ & $\begin{array}{l}\text { Licence to Teach and B achelorõ } \\
\text { Degree in Chemistry }\end{array}$ & A pplied Chemistry & $\bigoplus$ \\
\hline CEFET & $\begin{array}{l}\text { A nalytical } \\
\text { Chemistry }\end{array}$ & Chemical Engineering & $\bigoplus$ & 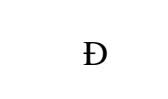 \\
\hline UESB & $\bigoplus$ & $\begin{array}{l}\text { Licence to Teach and B achelor } \tilde{\mathrm{s}} \\
\text { Degree in Chemistry }\end{array}$ & A nalytical Chemistry & 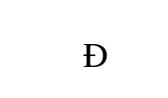 \\
\hline
\end{tabular}

Table 2. Chemistry Courses Offered by Institutions Studied

\footnotetext{
${ }^{9}$ For the purposes of this research we considered the year that CEFET's first course in Chemical Engineering started and not the course in Technical Analysis in Chemistry which was introduced in 2000.
} 
From these tables some preliminary analysis can be done, conducting to some surprising findings:

I. UFBA, UNEB and UESB are the only institutions that have postgraduate programmes specifically in chemistry

2. UEFS, despite having no undergraduate or postgraduate courses in chemistry, presents scientific publications indexed in the area prior to the first publications of CEFET and UESB.

3. UESC, although not offering postgraduate courses in chemistry, has researchers who have been connected for longer with research groups in chemistry.

4. The first indexed publication of UNEB in the area occurred two years before the creation of its undergraduate course, while at UFBA this did not happen until 16 years after.

\section{Results of the Scientific Production Analysis}

As shown in Table 3 below, UFBA is the university with the largest number of researchers working in this field (more than double the number of CEFET in second place) and also the largest number of research groups (more than double the number of UNEB in second place). UFBA also has in its faculty the largest number of researchers of chemistry linked to research groups (more than double the number of UNEB in second place) and the largest number of authors in the network of co-authorship (four times the number of UESB in second place). This shows the undisputed UFBA leadership, but the second place in the ranking is not evident from these numbers since each variable shows a distinct second place. It is important to note that the vast majority of the researchers are connected to research groups directly related to their institution. It is also important to note that, except for UESB where 100 per cent of its researchers are linked to its own research groups; in all of the other institutions surveyed the professors/researchers are also part of other institutions' research groups, which seems more natural given the multi-institutional and multidisciplinary nature of contemporary science.

\begin{tabular}{|c|c|c|c|c|c|c|}
\hline INSTITUTION & CEFET & UEFS & UESB & UESC & UNEB & UFBA \\
\hline Professors in chemistry (or similar) faculty & 24 & 10 & 5 & 19 & 16 & 52 \\
\hline Chemistry (or similar) faculty professors in formal research groups & 15 & 10 & 4 & 15 & 16 & 40 \\
\hline Percentage of professors in formal research groups & $62 \%$ & $100 \%$ & $80 \%$ & $79 \%$ & $100 \%$ & $76 \%$ \\
\hline A uthors in a co-authorship network & 67 & 159 & 168 & 103 & 96 & 708 \\
\hline $\begin{array}{l}\text { Professors in chemistry (or similar) faculty in their institutionõ co- } \\
\text { authorship network }\end{array}$ & 4 & 0 & 1 & 1 & 3 & 23 \\
\hline $\begin{array}{l}\text { Percentage of professors in chemistry (or similar) faculty in their } \\
\text { institution@̋ co-authorship network }\end{array}$ & $6 \%$ & $0 \%$ & $0.6 \%$ & $0.9 \%$ & $3 \%$ & $3 \%$ \\
\hline $\begin{array}{l}\text { Percentage of professors in chemistry (or similar) faculty in formal } \\
\text { research groups }\end{array}$ & $26 \%$ & $20 \%$ & $7 \%$ & $23 \%$ & $37 \%$ & $80 \%$ \\
\hline $\begin{array}{l}\text { Formal research groups with professors of chemistry (or similar) } \\
\text { faculty }\end{array}$ & 10 & 14 & 4 & 11 & 19 & 45 \\
\hline $\begin{array}{l}\text { Professors in chemistry (or similar) faculty awarded a CN Pq } \\
\text { productivity scholarship }\end{array}$ & 0 & 0 & 0 & 0 & 2 & 12 \\
\hline $\begin{array}{l}\text { Total number of participants (students and professors) in formal } \\
\text { research groups per institution }\end{array}$ & 521 & 409 & 84 & 309 & 678 & 1990 \\
\hline Total number of professors in formal research groups & 274 & 201 & 54 & 215 & 307 & 780 \\
\hline Total number of students in formal research groups & 247 & 208 & 30 & 94 & 371 & 1210 \\
\hline Percentage of students in formal research groups & $47 \%$ & $51 \%$ & $36 \%$ & $30 \%$ & $55 \%$ & $61 \%$ \\
\hline
\end{tabular}

Table 3. General Data for Researchers, Students and Formal Research Groups - 2008 
The institution with the highest percentage of its own professors/researchers in the co-authorship network in chemistry was CEFET, with a six per cent share, followed by UNEB and UFBA, each with three per cent. However, it is interesting to note the high degree of participation of researchers in research groups. In both UEFS and UESC 100 per cent of the professors are part of at least one formal research group. In this sense the lesser degree of participation refers to CEFET, where only 62 per cent of their professors are in at least one research group.

It is important to highlight the number of researchers awarded a CNPq productivity scholarship. It is very low, showing only UNEB with two researchers and UFBA with twelve researchers, which confirms Bahia's peripheral condition.

UFBA is also the institution with the largest number of researchers (professors and students) linked to research groups, with a total of I,990 members. In second place is UNEB with 678 researchers. Evaluating separately the number of professors and students involved with these groups results in the same positioning of these universities. By observing the percentage of students in relation to the number of professors in each research group, it appears that following UFBA's first place (6I per cent), UNEB is in a very close second place ( 55 per cent). In third place is UEFS, showing 51 per cent of students in research groups. Other analysis related to this table will be presented in the concluding section of the article.

The scientific production score (summarized in Table 4) of each institution was calculated by multiplying the number of articles published in each journal category, as established by the CAPES Qualis system, in the area of chemistry by the total points assigned to each category. Thus, the total number of $\mathrm{Al}$ - papers was multiplied by 10 points, 7.5 for $A 2$ - papers, 5.5 for BI, 3 for B2, 2 for B3, I for $\mathrm{B} 4$, and 0.5 for $B 5$. Articles in category $C$ received no score (the same procedure is adopted by the chemistry evaluation committee in CAPES).

\begin{tabular}{|l|c|c|c|c|c|c|}
\hline \multicolumn{1}{|c|}{ INSTITUTION } & CEFET & UEFS & UESB & UESC & UNEB & UFBA \\
\hline Indexed papers & 16 & 11 & 16 & 19 & 33 & 290 \\
\hline Total points & 88 & 66 & 25.5 & 94.5 & 140.5 & 1522 \\
\hline A verage points & 5.5 & 6 & 1,6 & 4.97 & 4.2 & 5.2 \\
\hline High impact papers $^{\text {High impact }}{ }^{10}$ papersÕpoints & 11 & 8 & 2 & 11 & 18 & 180 \\
\hline
\end{tabular}

Table 4. Production of Public Institutions Networks Indexed in Chemistry (2004-2008)

As noted, UFBA is the institution with the largest number of articles, more high impact articles (AI, A2 and BI-journals) and higher scores in both categories. Its number of articles during the period was ten times greater than that of UNEB in second place (18 articles with a total score of 122.5). UFBA shows the same preponderance in terms of the total number of papers published during the period. Between 2004 and 2008 the institution published 290 indexed articles. In second place UNEB published 33 articles.
Considering that the growth of cooperation among researchers and graduate programmes in search of scientific production contributes to the creation and diffusion of knowledge and that the intensity of their participation in scientific knowledge networks bears a strong correlation with their scientific productivity (Rossoni and Garrido Filho, 2009), we decided to evaluate these networks in the higher education institutions analyzed in this paper.

\footnotetext{
${ }^{10} \mathrm{High}$ impact papers are considered here as those published in journals classified in Qualis as AI,A2 and BI, the three highest of the eight existing levels.
} 


\section{Results of the Co-authorship Networks Analysis}

The UFBA network (see Figure 2) is quite complex and interdisciplinary as it has subgroups, and cliques, from various faculties and research areas. However, all of them have connections directly or indirectly related to the field of chemistry and, obviously, to scientific production indexed in this field by the ISI Web of Knowledge.

It can be seen in the figure below that some groups are poorly connected to the main component of this network. This is a characteristic of the so-called small world networks (Watts and Strogatz, 1998). In a small world's structure, differently from that of a random network, the distance between nodes does not increase with the increase of the network. These networks, however, tend to have high reciprocity and social cohesion among local actors. This cohesion contributes to the construction of global bit dense structures, which in turn will support the local structures of high density.
The local networks are formed by establishing direct links between researchers to develop research activities. Its composition is more related to social cohesion among a given number of actors, which is expected to have mechanisms of homophily and reciprocity influencing the creation of generative elements of institutionalized patterns of action (Rossoni and Machado-da-Silva, 2007, p. 2).

In the case of UFBA, however, what is most easily observed is the existence of a large group (main component) and a smaller one totally disconnected from the former. This does not occur in UESC's, CEFET's and UESB's networks, where the networks have been completely interconnected with high relative density and without any stronger evidence of the small world phenomenon.

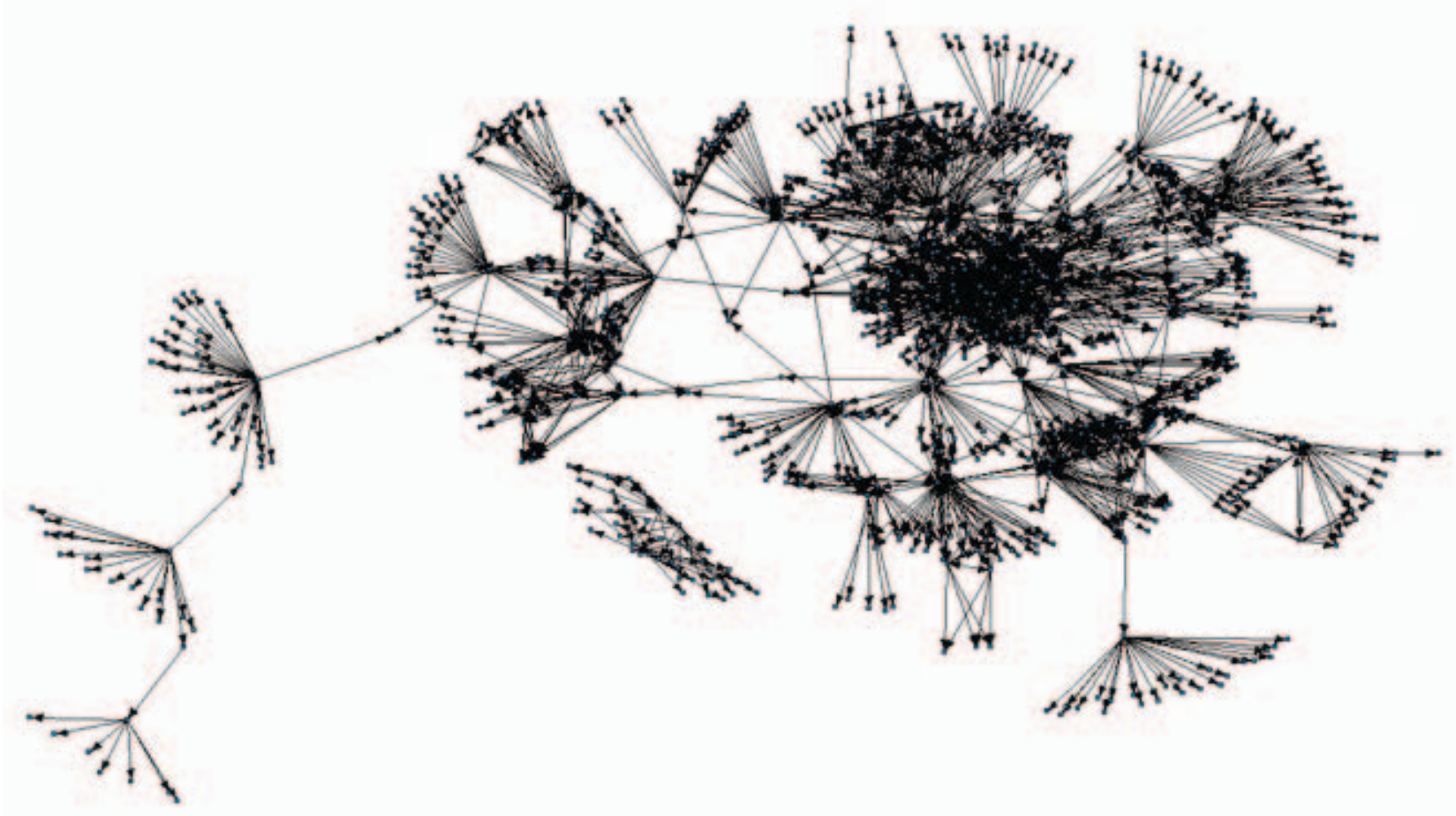

Figure 2. UFBA's co-authorship network in chemistry 2004-2008/ Source: Author's, elaborated from data from the ISI Web of Knowledge (20II) 
As UFBA is by far the largest and oldest university in the state so, it was decided to verify the participation of its researchers in the other institutions' networks. The results show that within the networks of other higher education institutions publishing scientific papers in chemistry in Bahia the participation of UFBA's researchers is quite small during this period. However, despite this finding, it can be said that these results show institutional interaction in the production of scientific knowledge, as suggested by Rossoni and Garrido Filho (2009).
The CEFET and UNEB (Figure 3) networks follow the same trend as the UESC network (Figure 4), being formed by a single component in which the participation of UFBA's researchers is also small relative to the total, although in a greater number and with a more central role.

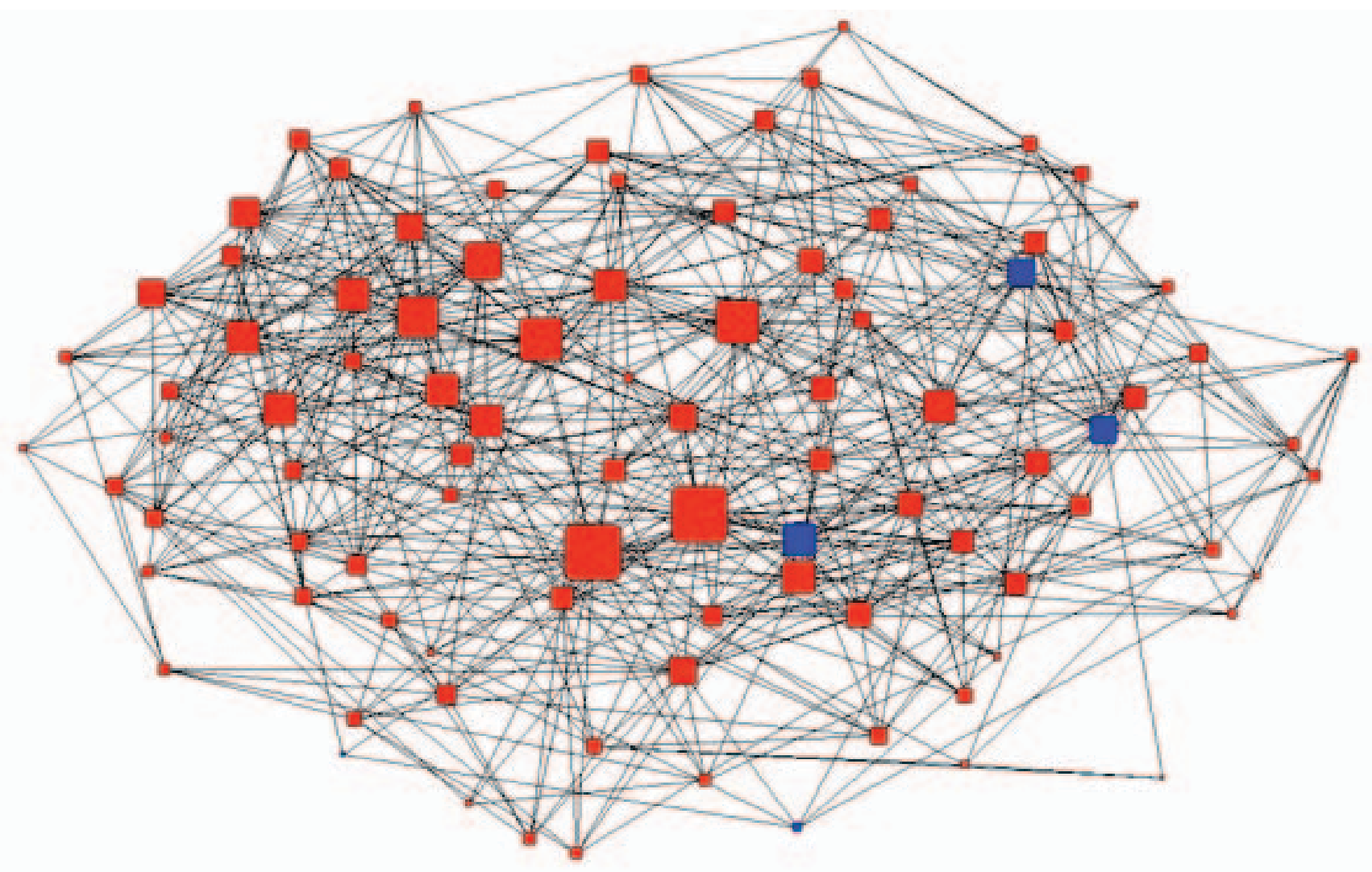

Figure 3. UNEB Co-authorship Network and participation of UFBA's researchers (blue nodes) - 2004-2008 Source: Author's, elaborated from data from the ISI Web of Knowledge (20II) "I

\footnotetext{
II In figures 3,4 and 5 nodes (authors) are represented by squares of different areas, commensurate with the degree of each co-author (number of connections with other nodes).
} 


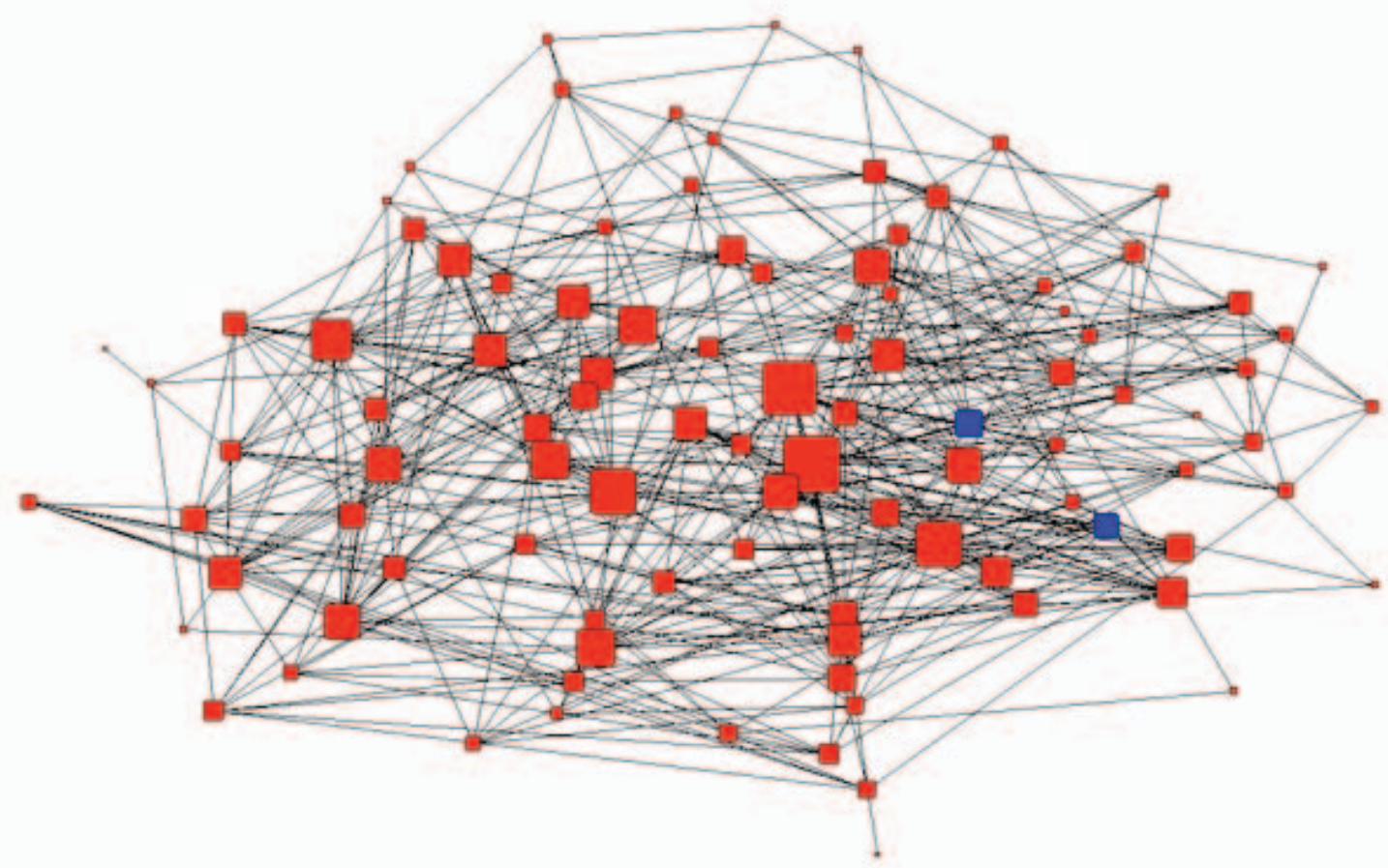

Figure 4. UESC Co-authorship network -2004-2008 and the participation of UFBA researchers (blue nodes)./ Source: Author's, elaborated from data from the ISI Web of Knowledge (20II)

In the case of the CEFET network (Figure 5) there is an absolutely homogeneous degree for all authors, including six UFBA representatives.

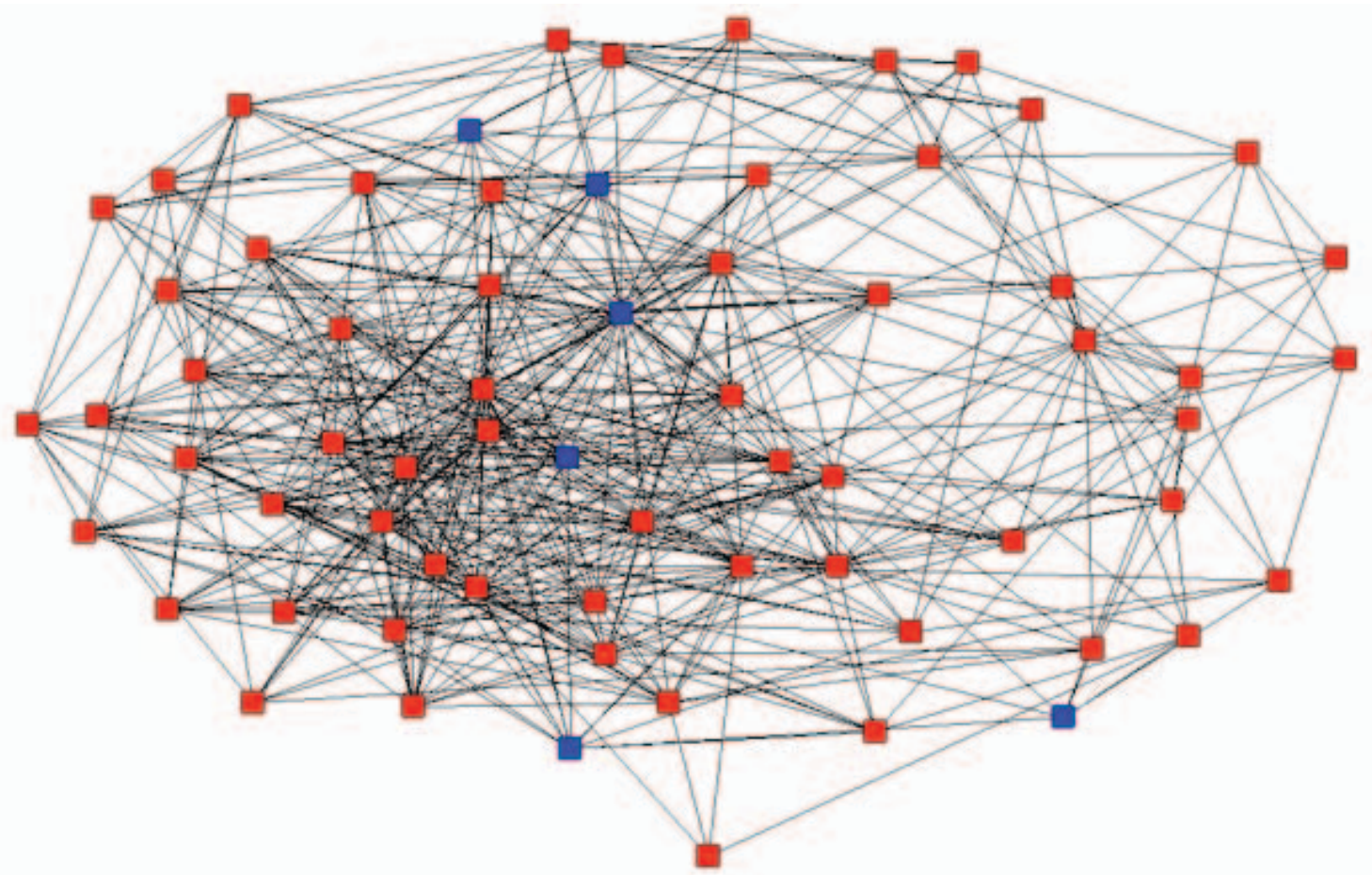

Figure 5. CEFET Co-authorship network and participation of UFBA's researchers (blue nodes) - 2004-2008 / Source: Elaborated from data from ISI Wok (20II) 
It is worth noting that UESB and UEFS, coincidentally the institutions with lower scientific production during the period (see Table 4) of the six institutions studied, also have apparently distorted data, such as the network density and the mean ties by author (see Table 5). These distortions, however, stem from the existence of the very large number of co-authors in some articles (we found a few articles indexed with more than 100 authors). This reality results in highly discrepant data compared with the rest of the networks analyzed. As a result, they cannot be considered in the analysis of social network metrics of this nature. For this reason the UESB and UEFS metrics are ignored when we calculate the correlations of these metrics with the scientific production, as presented below.

\begin{tabular}{|l|c|c|c|c|c|c|}
\hline \multicolumn{1}{|c|}{ Institution } & CEFET & UEFS & UESB & UESC & UNEB & UFBA \\
\hline Papers published by each network & 16 & 11 & 16 & 19 & 33 & 290 \\
\hline A verage number of authors & 4.18 & 8.36 & 3.27 & 4.90 & 2.15 & 1.85 \\
\hline N etwork global density & 11.96 & 29.75 & 22.46 & 4.88 & 5.93 & 0.39 \\
\hline A verage co-authorship per author & 17.64 & 77.00 & 121.82 & 10.33 & 12.92 & 7.3 \\
\hline
\end{tabular}

Table 5. Key Features of Structural and Relational Co-Authorship Networks in Public Institutions of Higher Education of the State of Bahia in the Field of Chemistry - 2004 to 2008

From Table 5 we found that CEFET is the institution with greater density in its co-authorship network, i.e., with the highest average number of ties between the authors. This would be expected as it has fewer articles published than the three universities with useful metrics in this period. In addition to these metrics, we performed degree calculations to identify the most central authors in each network. It was found that in the CEFET coauthorship network the author with the highest degree is De Andrade (degree 33). It is important to note that this author (who is also one of the ten most central in proximity and in intermediation) is a professor in the UFBA Faculty of Chemistry.

In the UESC network the author with the highest degree is Garcia (degree 43); he also presents the highest betweenness in this network. Interestingly, Ferreira, a professor at the UFBA Faculty of Chemistry, is among those with the highest degree in this network (this same professor is the author with the highest degree - degree 97 - in the UFBA network).

Regarding the UNEB network, there is a strong centrality of Korn, with the highest degree in centrality (degree 38 ) and the second in betweenness. Curiously, he is also among the highest degrees in the UFBA network.
What these paragraphs tell us is that there is still little interaction between the co-authorship networks of these institutions; however, these interactions have metrics that show how strategic the interaction is.

\section{Conclusions}

In an attempt to identify relationships between institutional, structural and relational characteristics with the networks' scientific production we tried several tests of correlation. Table 6 below shows the variables that showed higher correlations with production measured as a product of quantity multiplied by quality, as explained above. 


\begin{tabular}{|l|c|c|}
\hline \multicolumn{1}{|c|}{ Netw orksÕcharacteristics } & High impact production points & Total production points \\
\hline Global density & -0.567 & -0.564 \\
\hline A verage number of laces per author & -0.408 & -0.402 \\
\hline A verage co-authors per paper & 0.737 & 0.732 \\
\hline Y ears since first indexed paper & 0.992 & 0.991 \\
\hline $\begin{array}{l}\text { Number of professors in chemistry (or } \\
\text { equival ent) faculty }\end{array}$ & 0.932 & 0.930 \\
\hline Number of formal research groups & 0.960 & 0.958 \\
\hline
\end{tabular}

Table 6. Correlations between Productivity and Network Features

The correlation data that were found allow several conclusions. The first is a methodological one. Differentiating the scientific production as a whole from that with the greatest impact (only papers of best classified journal) does not seem to lead to significantly different results; it is therefore not an interesting methodological choice for this analysis.

Other results of correlation analysis reinforce some of the indications given in the literature review:

. Among the networks studied here it is observed that the density correlates negatively with the scientific production. According to the references used here (Moody, 2004; Wagner and Leydesdorff, 2005), this could be explained by the methodology we adopted here, where production is given by the product of the quality indicator multiplied by the number of publications. According to the authors, denser networks hinder the exchange of non-redundant knowledge and, consequently, the increasing of new knowledge stock in the network. On the other hand, denser networks facilitate the largest volume of production since the groups are more united and have a greater affinity between their members. Therefore, when using an indicator that encompasses quality and quantity to correlate with the density, we failed to find a high correlation; nevertheless, we found a clearly negative correlation.

- The average number of co-authors also negatively correlated with the production, apparently for the same reasons stated in the previous conclusion, i.e., favoring the volume but disadvantaging the quality as a result of a small flux of new knowledge in each group.
- The largest positive correlation found among all of the variables was the number of researchers awarded $\mathrm{CNPq}$ productivity scholarships in these networks. This finding is not surprising since only the most prominent researchers in the country in their respective areas of expertise are awarded these.

- The second highest correlation is somewhat surprising: the number of years since the institution of higher education first indexed a publication. In other words, in this group of institutions tradition may be seen as a proxy of higher scientific productivity.

. The third highest correlation found also reveals an important finding: the number of formal research groups, i.e., networks of co-authorship of Bahian public universities and other institutions in chemistry, are so much more productive than the larger number of research groups linked to them and formally registered in the CNPq. This is an important finding since the formalization of the groups is very easy, with no filters to distinguish the most serious emerging research groups from those who are only artificially formalized. Thus, despite the ease of registering groups with no concrete basis of joint works the existence of formal research groups seems to be very important for a considerable amount and quality of scientific production.

. Finally, there is the last variable with high correlation with production: the number of researchers. This seems to be crucial for an institution of higher education to be productive, the well-known concept of critical mass in research. People are more likely to make contact 
with others who are closer than those who are distant (McPhearson, Smith-Lovin, and Cook, 200I). This way, the probability of one researcher establishing relationships within the institution to which he belongs and within the same federative state is higher than with researchers who do not meet these conditions (Rossoni and Graeml, 2009).

\section{Final Considerations - Relating Scientific Knowledge Networks and the Local Innovation System in Bahia}

The importance of the continuous generation of knowledge for the development of any society is wellknown. Through this path one can offer new solutions to the problems of humanity with the development of technologies that will contribute to their human, social and economic development. In this way the articles published in scientific journals have a central role in transforming the tacit knowledge of their authors into systematic and explicit knowledge available to other researchers and knowledge workers.

Among the areas of greatest scientific production of Bahia chemistry stands out as one of the most important, reflecting the weight of the chemical and petrochemical industry in the state economy.

As shown throughout this text, researchers in cooperation networks influence each other, sharing perspectives and conditions for the deployment of their scientific work and the construction of substantive content. Therefore, this paper analyzed the landscape of scientific production in this area in the set of public institutions of higher education in Bahia, seeking to understand the correlation of production with the characteristics of institutions, faculties and graduate programmes translated into coauthorship networks aiming to draw useful conclusions to reinforce a fragmented local innovation system.

When we consider the compound of quality multiplied by quantity of scientific production (see Table 4), the Federal University of Bahia (UFBA) has absolute dominance with scientific production about ten times larger than that of the university in second place, while the scientific production of the institution in sixth place is a hundred times smaller than that of UFBA. At the same time the latter is the most important higher education institution in the second largest city in Bahia and the only one of the six institutions analyzed here without undergraduate and postgraduate degree courses in chemistry, but only courses in related fields (which explains its production indexed in the field). Rossoni and Graeml (2009) point out that in the scientific field the existence of postgraduate programmes in educational institutions provides more interaction between professors and students who interact through classes, meetings and research groups, among other ways, allowing a greater degree than when co-authoring relationships occur. Therefore, this is not a redundant observation as despite the increasing multidisciplinary nature of contemporary science, the existence of a formal and institutionalized field in this subject is still important for the universities and other higher education institutions in order to have significant scientific production in the field.

The literature reviewed here supports this observation since the lack of specific teaching units apparently prevents (or makes difficult) the tacit knowledge in the field of chemistry, potentially existing in UEFS, from being translated into explicit knowledge that is socialized and externalized in the form of scientific articles.

The fact that UEFS does not have courses in an area that is so important to the economy of its region is as amazing as the fact that all of the initiatives of UNEB, UESC, UESB and CEFET in this area are quite recent.

One of the factors that showed statistical correlation with the high scientific production is the number of researchers awarded CNPq productivity scholarships. This correlation justifies and supports the understanding that the role of scientific leaders is fundamental to the evolution of the field, as predicted by the literature reviewed: the importance of individual tacit knowledge in the process of collective construction of explicit knowledge (Nonaka and Takeuchi, 1997).

Another theoretical assumption was thus confirmed, the critical mass of researchers, namely: scientific production that is quantitatively and qualitatively relevant is only possible when a significant number of researchers are working in the same institution or geographic region. In this sense, according Louch (2000), organizational and institutional bonding is also a source of homophily, i.e., the same environment means that members of a given organization have issues in common and have fewer barriers to interaction, resulting in a higher frequency and proximity. I fact, a recent study by British and French researchers (Kenna and Berche, 2010, p. 6) concluded 
that "the collaborative effect is an order of magnitude stronger than that of individual caliber. This means the strength of the community is greater than the sum of its parts" (Jump, 2010). This is an important consideration for those who seek to structure the local innovation system of Bahia, especially at the time when Bahia starts operation of its first technology park.

Finally, we observe that local and regional systems of innovation, whether fragmented or not, depend crucially on the existence of research-active and effective universities. In this regard it is worth noting that this research clearly shows (Figures 3, 4 and 5) something that should be the object of the science, technology and innovation policy in Bahia, and possibly in other peripheral regions of developing countries: the stimulus for cooperation between the institutions of science and technology, particularly the cooperation between universities and other higher education institutions on research in their own region. This is an important conclusion of this research that contributes to the solution of the aforementioned "lack of clear criteria for allocation of state resources in Science \& Technology" (Lima and Teixeira, 200I, p. 155) and eventually to its modeling as proposed by Loiola and Ribeiro (2007) as discussed in the introduction of this paper. In the case studied here the largest university, even with some national prominence in chemistry, does not seem to play a central role in neighboring institutions' research and co-authorship networks. This role is probably being played by universities located in the most developed regions in the country (such as Rio and São Paulo) which have a research agenda that was developed in their headquarters and concerned with their own regional necessities. As mentioned before, Plonski (1994) shows that cooperation should be perceived by governments as strategically important to the economic and social viability of some regions. It reinforces the need for public policies concerned to improve collaboration between local universities in Bahia, particularly in the case of UFBA.

Among the limitations of this research it is worth mentioning the fact that we failed to generate reliable information and conclusions about the phenomenon of homophily and the institutionalization of practices and values in the networks studied.

Although the fact that we found strategic insertion of UFBA's leading researchers in other state universities.

\section{References}

ADAMS, J., \& King, C. (2009). The global research report - Brazil. Leeds, UK, Thomson Reuters. Retrieved from Thomson Reuters website: http://researchanalytics. thomsonreuters.com/m/pdfs/GRR-Brazil-Jun09.pdf

ALBUQUERQUE, E. (1996). Sistema nacional de inovação no Brasil: uma análise introdutória a partir de dados disponíveis sobre C\&T. Revista de Economia Política, 16(3), 56-71.

ASHEIM, B. T., \& Isaksen, A. (2002). Regional innovation systems: the integration of local 'sticky' and global 'ubiquitous' knowledge. The Journal of Technology Transfer, 27(I), 77-86. doi: 10.1023/A:I013100704794

BARAB, S., Thomas, M., \& Merrill, H. (200I). Online learning: from information dissemination to fostering collaboration. Journal of Interactive Learning Research, 12(I), 105-143.

BARBOSA, M. T. S., Byington, M. R. L., \& Struchiner, C. L. (2000). Modelos dinâmicos e redes sociais: revisão e reflexões a respeito de sua contribuição para o entendimento da epidemia do HIV. Cad. Saúde Pública, 16(sI), 37-5I. doi.org//0.1590/S01023 IIX2000000700004

CASSIOLATO, J. E. (1996). A relação universidade e instituições de pesquisa com o setor industrial: uma abordagem a partir do processo inovativo e lições da experiência internacional. Brasília: Sebrae.

DAVENPORT, T., \& Prusak, L. (1998). Conhecimento empresarial: como as organizações gerenciam o seu capital intelectual. Rio de Janeiro: Campus.

NOOY, W. de, Mrvar, A., \& Batagelj, V. (2005). Exploratory social network analysis with Pajek. New York: Cambridge University Press.

EDQUIST, C. (1997). Systems of innovation: technologies, institutions, and organizations. London: Pinter.

FREEMAN, C. (1995). The national system of innovation in historical perspective. Cambridge Journal of Economics, (19), 5-24. 
GNYAWALI, D., \& Madhavan, R. (200I). Cooperative networks and competitive dynamics: a structural embeddedness perspective. Academy of Management Review, 26(3), 43I-445. doi: 10.2307/259186

HAYASHI, M. C. P. I., Hayashi, C. R. M., \& Lima, M. Y. (2008). Análise de redes de co-autoria na produção científica em educa. Liinc em Revista, 4(I), 84-103. Retrieved from: http://revista.ibict.br/liinc/index.php/liinc/ article/viewFile/274/179

JUMP, P. (2010). Truth in numbers: study pinpoints 'critical mass' for research success. Retrieved from Times Higher Education website: http://www.timeshighereducation. co.uk/story.asp?storycode $=412390$

JUN, J., Shanchao, W., \& Jin, C. (20II). International university-industry collaboration to bridge $R \& D$ globalization and national innovation system in China. Journal of Knowledge-based Innovation in China, 3(I), 5-14. doi: 10.1I08/I756/4IIIIII20837

KENNA, R., \& Berche, B. (20I0). The extensive nature of group quality. EPL, 90(5), I-6. doi: 10.1209/0295$5075 / 90 / 58002$

LEE, S., \& Bozeman, B. (2005). The impact of research collaboration on scientific productivity. Social Studies of Science, 35(5), 673-702.

LEYDESDORFF, L., \& Etzkowitz, H. (1998). The triple helix as a model for innovation studies. Science and Public Policy, 25(3), 195-203.

LIMA, M. C., \& Teixeira, F. L. (200I). Inserção de um agente indutor da relação universidade-empresa em sistemas de inovação fragmentado. Revista de Administração Contemporânea, 5(2), 135-I56. doi: 10.1590/SI4I565552001000200007

LOIOLA, E. R., \& Ribeiro, M. T. F. (2007). A Science, Technology \& innovation proposal for the state of Bahia: a transversal approach. Journal of Technology Management and Innovation, I(2), 80-9I.

LOUCH, H. (2000). Personal network integration: transitivity and homophily in strong-tie relations. Social Networks, 22(I), 45-64. doi: 10.1016/503788733(00)00015-0
LUNDVALL, B. A. (1992). National innovation systems: towards a theory of innovation and interactive learning. London: Pinter.

MCPHEARSON, M., Smith-Lovin, L., \& Cook, J. M. (200I). Birds of a feather: homophily in social networks. Annual Review of Sociology, 27(I), 4I5-444. doi: 10.1146/ annurev.soc.27.1.4I5

MERTON, R. K. (1973). The sociology of science: theoretical and empirical investigations (Edited by $\mathrm{N}$ Storer.) Chicago: University of Chicago Press.

MIETTINEN, R. (2002). National innovation system: scientific concept or political rhetoric. Helsinki: Edita.

MOODY, J. (2004). The structure of a social science collaboration network: disciplinary cohesion from 1963 to 1999. American Sociological Review, 69(2), 213-238. doi: $10.2307 / 3593085$

NONAKA, I., \& Takeuchi, H. (1997). Criação de conhecimento na empresa: como as empresas japonesas geram a dinâmica da inovação. Rio de Janeiro: Campus.

PATEL, P., \& Pavitt, K. (1994). The nature and economic importance of national innovation systems. STI Review OECD, 3(I4), 9-32. doi: 10.1080/10438599400000004

PIMENTA, R., Santos, G., Oliveira, A. C., \& Queiroz, G. (2004). Transformando conhecimento em conhecimento: Utilizando redes de relacionamento para captação e geração de conhecimento focado nas estratégias empresariais. Anais do Workshop Internacional sobre Inteligência Empresarial e Gestão do Conhecimento na Empresa. Recife, PE, Brasil, 5.

PLONSKI, G. A. (1994). Cooperação universidadeempresa na lberoamérica: estágio atual e perspectivas. Anais do Simpósio de Gestão da Inovação Tecnológica, São Paulo, SP, Brasil, 18.

KENNA, R., \& Berche, B. (20I0). The extensive nature of group quality. EPL, 90(5), I-6. doi: 10.1209/02955075/90/58002

RAPINI, M. S., \& Righi, H. N. (2006). O diretório dos grupos depesquisa do CNPqea interação universidade-empresano Brasilem 2004. Revista Brasileira de Inovação, 5(I), I3I-I56. 
ROSSONI, L., \& Machado-da-Silva, C. L. (2007). Coesão estrutural e construção do conhecimento científico no campo da estratégia. Anais do Encontro de Estudos em Estratégia, São Paulo, SP, Brasil, 3.

ROSSONI, L., \& Garrido Filho, E. R. (2009). Cooperação entre programas de pós-graduação em administração no Brasil: evidências estruturais em quatro áreas temáticas. Revista de Administração Contemporânea, 13(3), 366390. Retrieved from http://www.scielo.br/pdf/rac/v/3n3/ vl3n3a03.pdf. doi: 10.1590/SI4I5-65552009000300003

ROSSONI, L., \& Graeml, A. (2009). A influência da imersão institucional e regional na cooperação entre pesquisadores no Brasil. Redes - Revista hispana para el análisis de redes sociales, 16(9), 229-249.

SABATO, J., \& Botana, N. (1968). La ciência e la tecnologia em el desarrolo futuro de America Latina. Revista de Integración, 15-36.

SCOTT, J. (2000). Social network analysis: a handbook (2nd ed.). London: Publications.

WAGNER, C. S., \& Leydesdorff, L. (2005). Network structure, self-organization, and the growth of international collaboration in science. Research Policy, 34(10), 1608-1618. doi:10.1016/j.respol.2005.08.002

WASSERMAN, S., \& Faust, K. (1994). Social network analysis: methods and applications. Cambridge: Cambridge University Press.

WATTS, D. J., \& Strogatz, S. H. (1998). Collective dynamics of 'small-world' networks. Nature, 393, 440-442. doi: 10.1038/30918 
J. Technol. Manag. Innov. 20I2, Volume 7, Issue I 